\title{
Construction of Supply Chain of Fresh Agricultural Products of CR Vanguard Supermarket Based on Computer Information Platform
}

\author{
Zhang Peng, Kang Jian \\ Department of Information and Technology Engineering, Tang Shan Vocational and Technical \\ College, Tangshan Hebei 063004, P.R.China
}

Keywords: information system; supermarket; supply chain; computer

\begin{abstract}
Supermarket chain supermarket fresh agricultural products logistics has always been the main reason for increasing the cost of supermarket, on the basis of information system theory, the modern computer technology is used to build information platform, improve the supply of fresh agricultural products of CR Vanguard Supermarket, reduce the cost of the supply of fresh agricultural products to maximization, supermarket logistics management modernization is realized. Meanwhile, the integration of VRM, ERP and public information platform is obtained to build agricultural products supply chain information platform, according to the existing problems, the reasonable suggestions are proposed to maximize the effectiveness of supermarket supply chain.
\end{abstract}

\section{Introduction}

The development of agricultural modernization is an important task of the "Twelfth Five Year Plan". Because of the level of agricultural modernization is low, the logistics of agricultural products is not developed, and the supply chain is not perfect, the farmers' income is low. Supply chain has become an important factor restricting the circulation of fresh agricultural products, and as the main output of fresh agricultural products, the supermarket chain play an important role in the supply chain. Chain The supermarket establish a safe, efficient, standardized fresh agricultural products supply chain can fundamentally improve the flow of information, thereby improving the whole fresh agricultural products logistics, speed up the turnover of cash flow. So that fresh agricultural products achieves the maximum value through the supply chain of information management system. The farmers can increase income, agricultural modernization can be realized.

\section{Information systems and relevant supply chain theory}

\subsection{Information systems theory}

Information management system (ERP) is the running mode of modern enterprise management. It uses modern computer technology, to build a wide range of applications within the company, it has a highly integrated system, covering the customer, project, inventory and procurement and supply management, through the optimization of enterprise resources to achieve maximum resource efficiency. Distribution information management (VRM) is a kind of authentication user relationship marketing service system based on big data technology, which is mainly oriented to large enterprises.

\subsection{Supply chain related theory}

The supply chain refers to the connection or business convergence of the goods before reaching the consumer. It is the core business, through the control of information flow, logistics, capital flow, from the procurement of raw materials, semi-finished products or finished products, and finally send to consumers by the sales network. In the hands of suppliers, manufacturers, distributors, retailers, until the end users, a whole function network chain structure is formed.

\subsection{Information systems supply chain}

To build a fresh agricultural product supply chain information management system, it is necessary to bring together ERP, fresh agricultural products logistics, VRM, public information and other related functions, to build a comprehensive management information system. The 
management information system includes three stages of production, supply and sales, is connecting link between farmers, supermarkets and consumers, which not only control the source of fresh agricultural product related information, and runs through the whole process of the supply chain with agricultural products, the agricultural products customer information, such as quantity, price, location, transit stations, order management, purchase, transfer, storage information are collected. In the process of turnover in the draft of agricultural products, cash, cost, account, business accounting, profits and other information are taken with financial management, thus, whole process management of the fresh agricultural production goods supply chain is obtained.

The information system is used to establish a protocol base for fresh agricultural products, through a perfect logistics network to achieve docking of agricultural products, the establishment of terminal outlets of a network is obtained, improve the relevant rules and procedures. Establish different standards for different agricultural products, standardized operation, the rural credit cooperatives and supermarket terminals connected to establish a stable cooperative relations, while ensuring the quality of fresh agricultural products to ensure consumer food safety, the whole supply chain of fresh agricultural products traceability is realized, it has supervision of the circulation process of agricultural products.

Fresh agricultural product supply chain information system is a complex and systematic project, it needs to establish a standardized supply chain system, to meet the needs of farmers, logistics suppliers, supermarkets, consumers, and according to the actual situation of changes in the supply chain. It needs to establish a stable long-term cooperative relationship with partners, to solve the source of agricultural products logistics problems, give full play to the role of information systems, to achieve good communication between the parties.

\section{Fresh agricultural products supply chain status of CR Vanguard Supermarket}

With the development of rural urbanization, the change of agricultural products structure is driven, to promote the introduction of a variety of household income policy, while the state also is stressed the need to ensure the stability of agricultural prices, to prevent agricultural prices rose too fast, and promote the consumption of agricultural products. How to promote the increase of farmers' income and ensure the smooth development of economy has become an issue of the times. The supply of fresh agricultural products has been in the status of high input, high cost, high loss rate, low efficiency, the management of fresh agricultural products is not scientific, organization is decentralized, it cannot products based on the needs of the market, resulting in complex links, unstable prices, it cannot guarantee the quality and safety of the products. But the fresh agricultural products always affect the daily life of urban residents, while it is the main source of income of farmers. If we can realize the modernization of agricultural products logistics, we can make a big step forward in China's agricultural modernization. At present, the way to buy agricultural products in China is mainly farmers market, and it still has a big gap between developed countries in the supermarket supply as current situation. China's supermarket supply chain needs to pay attention to the supply of fresh agricultural products, but there are still the following problems:

(1) It cannot establish a stable and cooperative relationship. CR Vanguard Supermarket and fresh agricultural products logistics suppliers need establish a stable and long-term cooperative relationship, and it is the key to achieve the rapid circulation of fresh agricultural products. Stable cooperative relationship can optimize the supply chain, realize the sharing of information, so that the distribution of fresh agricultural products rationalization. All aspects of the supplier to through the protocol to achieve stability of procurement and sales, to ensure the high quality of fresh agricultural products supply, how to establish terminal chain supermarkets, fresh agricultural products main producer and supplier for subordinate relations of cooperation, in order to achieve the maximization of the value of the supply chain, it has become the biggest problem now.

(2) The differences management organization has different cooperation subjects. Nature of the vanguard to supermarket chain, suppliers, rural cooperatives are not the same, their operation and management in different ways, different mode of operation may lead the parties in cooperation in the process of friction. Chain supermarket management is characterized by high organization, high 
order, high standardization, high modernization, and the characteristics of agricultural cooperatives is the manual operation, loose organization, the operation of the lack of standardization, high degree of human, which makes the two organizations have differences in cooperation, prone to conflict. In cooperation, the two sides cannot blindly compromise in order to cooperate with each other in the way of operation, and should be in the operation of the process of exchange and communication, information sharing, and promote the development of the two sides to adapt to the development of modern logistics. Meet the modern supply chain, based on the continuous improvement of operational efficiency, and it needs to build the information management system, to achieve the goal of a win-win situation.

(3) Establishment of supply chain standard for fresh agricultural products. Fresh agricultural products and industrial products are different, it cannot make a significant quantitative treatment, because of different origin, different varieties, and even the growing season may cause the quality of fresh agricultural products are different, in order to optimize the fresh products chain in process of supermarket operation, it is necessary to establish a standardized operating procedures, the development of recognized standards is obtained, so that the chain supermarket, farmers, suppliers according to the standardized operation. At the same time, the establishment of the supply chain is adaptive to the actual situation of business standards, with these norms and standards as the resources, the various aspects of information processing are recorded, and it can enhance the efficiency of the whole supply chain operations, improve the overall interests.

(4) How to monitor the operation of the supply chain. Chain supermarket should take supervision for the operation of the whole supply chain, in order to ensure the quality of fresh agricultural products, control the loss of each link. Therefore, we should have a corresponding supervision system, improve the quality inspection system, various aspects of the supervision of the network is established, the source of fresh agricultural production, information, quality, procurement, sales, transportation, storage and supervision can be tracked in the whole process, to ensure that the operation of all aspects can be recorded and can be traced back.

(5) To ensure the efficiency and cost of fresh agricultural products logistics. As the development of modern logistics in China is still in the primary stage, the level of logistics is low, the loss in the transport process is high, and the operation is difficult to achieve standardization, the efficiency of the supply chain is reduced. The loss rate of fresh agricultural products in China is about 25\% 30\%, five to six times of the developed countries, China's agricultural development and modernization of the distance is still relatively large, a lot of work is still stuck in the manual stage.

For the CR Vanguard Supermarket, in order to establish a perfect cold chain logistics, improve the logistics of modern equipment level, reduce logistics cost, at the same time, a simple processing center is established, to carry on the processing of rice, increase the value of the logistics chain, improve the logistics, commerce and cash flow of operation. In the supply chain, we are looking for innovation. Therefore, the chain supermarket should take advantage of its own direct contact with consumers, timely grasp the market changes, timely adjust the supply chain according to changes in consumer demand, and establish a demand oriented supply chain system. The modern logistics equipment is taken in advantage, to achieve the economic benefits and social value of the whole supply chain. 


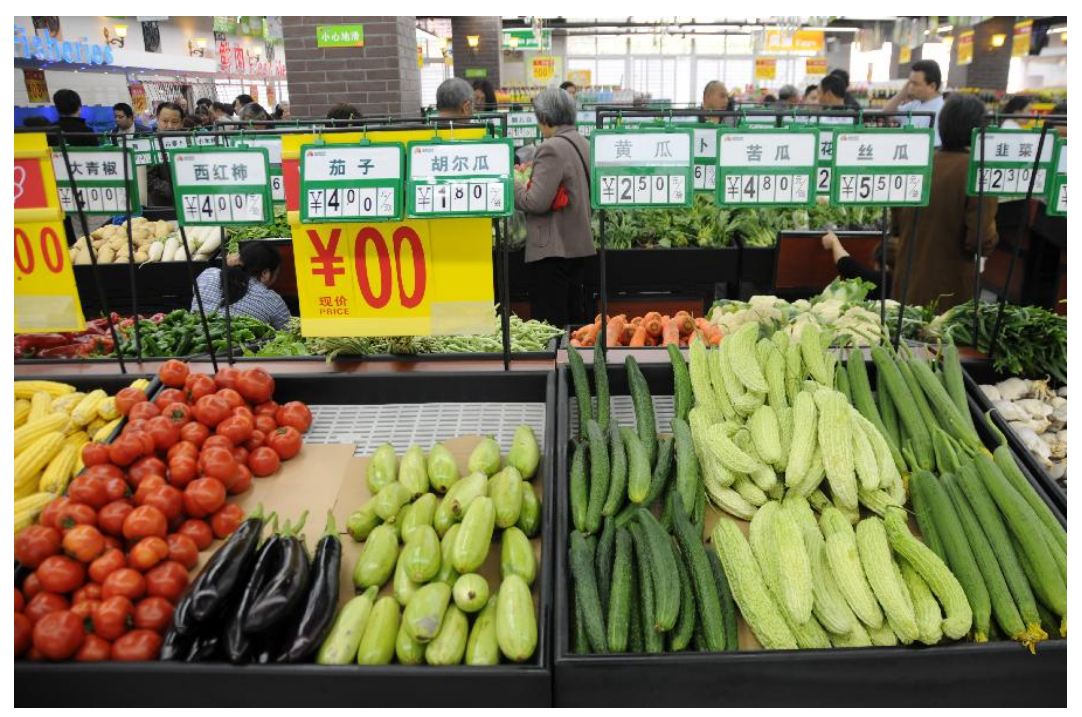

\section{Construction of fresh agricultural products supply chain information system for CR Vanguard Supermarket}

The establishment of chain supermarket fresh agricultural product supply chain is taken based on information management system. Here, the author takes the CR Vanguard Supermarket as example, summarized the operation of standardization, the process supervision and supply chain management, and information integration are obtained in the management system, it is summed up as following:

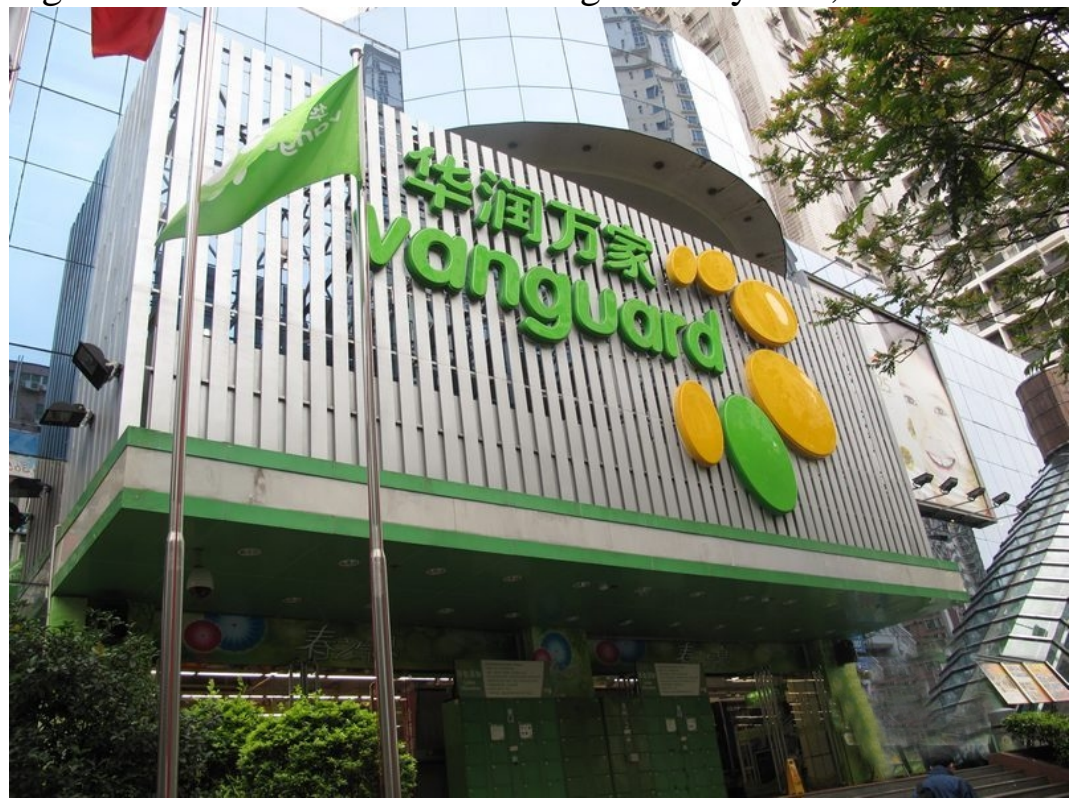

(1) Integration of resources information system

For the CR Vanguard Supermarket, circulation of fresh agricultural products is the integration of various resources, in the production, transportation, consumption and sales process, according to a certain standard set of information resources at all stages, and to collect the information to collate, filter out useless information, analysis of the use of information in the process of production, transportation, consumption and sales. Therefore, the information system information we can get from inside and outside the supply chain, the internal is based on the existing relationship, the traditional mode of procurement reform, the rational allocation of resources; external information is mainly from the agricultural information platform, the price of agricultural products, supply and related information to form the basic database of supermarket chain fresh agricultural products.

The information system should be constructed according to the characteristics of different stages of the supply chain, and define the concept and format of standard information in different stages, establish the corresponding standards for the collection and use of information, set up the right of use of information, and ensure the standardization of information operation. According to the needs 
of information users and users, so that the size of the information is in accordance, so that all aspects of the information can be linked to ensure that information sharing. The number of information, the establishment of origin, products, producers to the logistics, goods, logistics business relations network, the spatial information mobile transformation is realized, the establishment of information identification system is completed.

(2) Establishment of a process monitoring system

After establishment of basic information system of the CR Vanguard Supermarket, the quality of fresh agricultural products is carried out a unified management. In the country of origin, first of all, the pesticide residue of fresh agricultural products, product quality inspection; in the process of transportation, the quality of fresh agricultural products logistics sampling; in the process of storage, the loss of the product inspection; after the arrival of the chain supermarket, once again check loss, fresh and fresh agricultural products shelf life, so as to realize the whole process of monitoring. These provide the information basis and source for the improvement of logistics, and it is better to complete the track record of these information.

(3) Establishment of supply chain management information system

The CR Vanguard Supermarket has established supply chain management system with itself as the leading, according to the demand of fresh agricultural products, including planting, harvesting, procurement, transportation, storage, transportation and sales with 7 stages. The traditional ERP system takes the enterprise's logistics center as the starting point, including the sales and distribution management (SD), statistics/business data warehouse (BW/BI), financial accounting (FI) and management accounting (CO) and other modules. However, these functions cannot meet the requirements of fresh agricultural products, Relationship Management is established through the establishment of supplier relationship management platform (VRM:Vendor) to the ends of the information system, in the upstream, with suppliers and logistics business cooperation, planting, storage, and other relevant information for management, in the downstream, information platform for consumers, online customer information management can meet the supply demand of fresh agricultural products.

\section{Construct information system of supply chain for fresh agricultural products}

Through the above discussion, it is concluded that: in the actual operation process, the infrastructure should be matched with the production and operation ability, so the construction of the information system of the supply chain should match with the ability. Here, it refers to the "three networks", " Three standards " and "five chains" construction mainly.

Three network refers to the fresh agricultural products based on "agricultural super docking" agreement base network, circulation phase of the logistics network, terminal sales outlets. Supermarket chain of fresh agricultural products mainly takes from agricultural cooperatives or wholesale suppliers. The quality, quantity and production of fresh products, which are purchased by wholesale suppliers, is uneven, and the relevant information is scarce, so it is impossible to realize the origin and the price of fresh produce. Through long-term cooperation with the origin, the signing of the agreement, as well as the management of each other's running in, the establishment of a credit cooperative relationship, constitute the basis of a stable supply chain. Chain supermarket through a variety of ways and origin of cooperation, the formation of a large logistics network, the logistics chain of each link contain the information such as quality, time, cost control, to achieve the maximization of the value of the supply chain, and the chain supermarket can use its own terminal sales characteristics to achieve the scale of sales, increase the income of both sides.

"Three standards" is that the product of different circulation stage to establish different quality grade standard, supply chain operation standard and logistics equipment standard. The formulation of the relevant standards is the premise of the plan, but also to develop the supply chain of the basis of the specific links, the establishment of information systems can meet the requirements. Through the standardization of the supply chain operation, it can reduce the waste of resources, and improve the efficiency of management, while ensuring the quality of fresh products. The standardization of logistics tools and equipment, it can reduce the loss in the transport process, shorten the days of 
turnover, save time, improve the efficiency of the whole supply chain.

"Five chains" refers to the stable credit chain from the rural cooperatives to the chain supermarket chain, agricultural products from the plant to the end customer safety management chain, product transport the whole process traceability chain, product circulation process value tracking management chain, high loss of fresh agricultural products supply cold chain. Only do a good job in the five chains, the stability of the circulation of agricultural products can be ensured, and the circulation and sharing of information can be achieved. The stable credit chain of chain supermarket is taken on the basis of long-term cooperation, and the product supply chain can ensure the quality of fresh produce and meet the needs of consumers for food safety. Chain supermarket must fully grasp the source information, grasp the information of the dynamic, the full range of tracking, the cost concept throughout the entire supply chain, and continuously optimize the value of the supply chain.

\section{Conclusions}

The fresh agricultural products circulation supply information management system of the CR Vanguard Supermarket is a comprehensive project related to ERP information systems VRM public information platform. It brings together a variety of product information and norms, which throughout the entire process with plant, procurement, logistics, storage, sales. It is the link between farmers, cooperatives, chain supermarkets, logistics suppliers. And according to the change of the actual situation, the integration and adjustment can be carried out to meet the interests of many parties, and realize the maximization of the social value. The supply chain information management system of supermarket chain is the inevitable choice for the modernization of agriculture and the modernization of supermarket chain management.

\section{References}

[1] Xing Li.Study on Information Recommendation System Based on Cloud Computation [J].Logistics Technology.2013;32(2):185-188.

[2] YANG Jian.Application of Cloud Computing in Modern Logistics [J].Logistics Technology.2012,31(11):415-416,449.

[3] Ying-Hua Chang.Adopting co-evolution and constraint-satisfaction concept on genetic algorithms to solve supply chain network design problems [J].Expert Systems with Applications,2010,37(10):6919-6930.

[4] C.Y.Lam,S.L.Chan,W.H.Ip,C.W.Lau.Collaborative supply chain network using embedded genetic algorithms[J].Industrial Management\&Data Systems,2008,108(8):1101-1110.

[5] Antonio Costa,Giovanni Celano,Sergio Fichera Enrico Trovato.A new efficient encoding/decoding procedure for the design of a supply chain network with genetic algorithms[J].Computers\&Industrial Engineering,2010,59(4):986-999. 